Sādhanā Vol. 38, Part 3, June 2013, pp. 359-375. (c) Indian Academy of Sciences

\title{
Apparatus and method for heat-run test on high-power PWM converters with low energy expenditure
}

\author{
J S SIVA PRASAD* and G NARAYANAN \\ Department of Electrical Engineering, Indian Institute of Science, \\ Bangalore 560012, India \\ e-mail: sivaprasad.iisc@gmail.com; gnar@ee.iisc.ernet.in
}

MS received 13 June 2011; revised 1 January 2013; accepted 5 April 2013

\begin{abstract}
Before installation, a voltage source converter is usually subjected to heat-run test to verify its thermal design and performance under load. For heat-run test, the converter needs to be operated at rated voltage and rated current for a substantial length of time. Hence, such tests consume huge amount of energy in case of high-power converters. Also, the capacities of the source and loads available in the research and development $(\mathrm{R} \& \mathrm{D})$ centre or the production facility could be inadequate to conduct such tests. This paper proposes a method to conduct heat-run tests on highpower, pulse width modulated (PWM) converters with low energy consumption. The experimental set-up consists of the converter under test and another converter (of similar or higher rating), both connected in parallel on the ac side and open on the dc side. Vector-control or synchronous reference frame control is employed to control the converters such that one draws certain amount of reactive power and the other supplies the same; only the system losses are drawn from the mains. The performance of the controller is validated through simulation and experiments. Experimental results, pertaining to heat-run tests on a high-power PWM converter, are presented at power levels of $25 \mathrm{kVA}$ to $150 \mathrm{kVA}$.
\end{abstract}

Keywords. Voltage source converter; pulse width modulated converter; pulse width modulation; high-power converter; heat-run test; energy conservation.

\section{Introduction}

A three-phase pulse-width modulated (PWM) voltage source converter (VSC) is shown schematically in figure 1. In this converter, the power could flow either from the dc side to the ac side, or in the opposite direction (i.e., ac to dc). Due to its bi-directional power flow capability, this is used in a wide variety of applications, such as un-interruptible power supplies (UPS), static

*For correspondence 


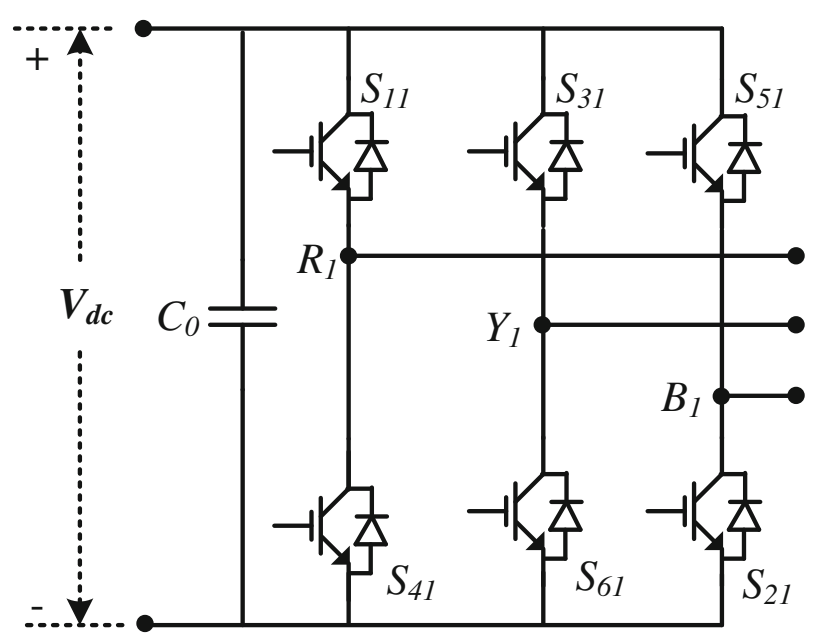

Figure 1. Schematic diagram of a voltage source converter (VSC).

compensators (STATCOM), active rectifiers or front-end converters (FEC), distributed generation from renewable energy sources, and motor drives (Rashid 2001).

In UPS and motor drive applications, the three-phase load (or motor) is connected on the ac side. In case of UPS, the VSC converts dc into fixed frequency ac $(50$ or $60 \mathrm{~Hz})$. In case of motor drives, dc voltage is converted into a variable-voltage, variable-frequency ac supply (Rashid 2001).

Conventionally, diode bridges or thyristor converters are used for rectification. In this case, the line current drawn from the mains is highly distorted, and the power factor is poor. A VSC can be used as an active PWM rectifier (figure 2) for ac to dc conversion, ensuring high power factor and low current distortion. The ac terminals of the converter are connected to the grid through filter inductors as shown in figure 2. The principle of operation of a unity power factor (UPF) rectifier is illustrated by the phasor diagram in figure $3 \mathrm{a}$.

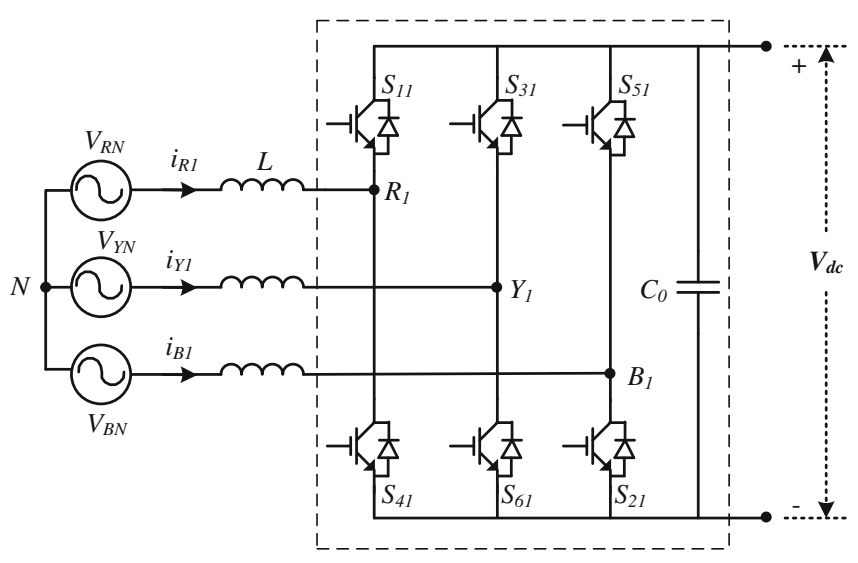

Figure 2. Schematic diagram of a front-end converter (FEC). 


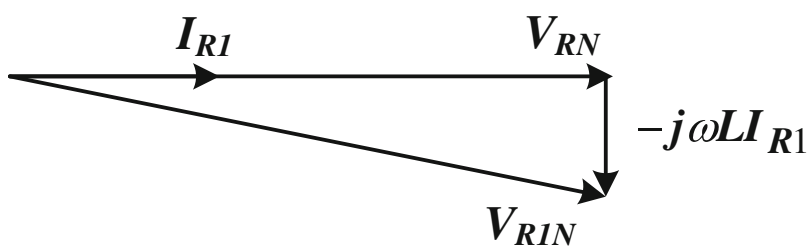

(a)

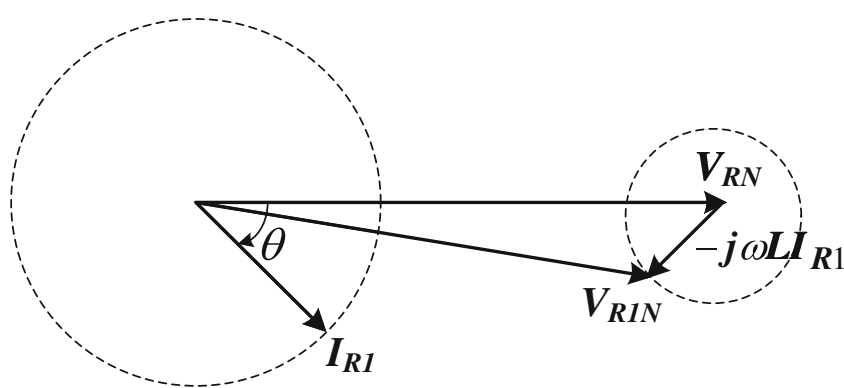

(b)

Figure 3. Phasor diagram of a grid-connected VSC (a) operation at unity power factor; (b) operation at an arbitrary power factor angle.

If the converter has to draw certain amplitude of fundamental current $\left(I_{R 1}\right)$ at UPF from the mains, then the fundamental component of the converter terminal voltage $\left(V_{R 1 N}\right)$ should be as indicated in figure $3 \mathrm{a}$. The harmonic components of the terminal voltage of the converter are filtered by the line inductors, and hence the line current is nearly sinusoidal (Siva Prasad et al 2008).

More generally, the converter can draw line currents at any power factor through suitable control of the terminal voltage $V_{R 1 N}$ as illustrated in figure $3 \mathrm{~b}$. The line current is made to lead the supply voltage by $90^{\circ}$ to supply reactive power to the mains in case of static VAR compensator (STATCOM) (Sensarma et al 2001). If the current is out of phase $\left(\theta=180^{\circ}\right)$ with the supply voltage, then the power flow is from the dc to the ac side. This mode is useful in grid-connected photovoltaic converters (Kadri et al 2011).

In grid-connected wind energy applications, two back-to-back PWM converters with a common dc bus are generally used (Portillo et al 2006). The machine-side converter converts the variable-frequency, variable-voltage ac generated by the wind turbine driven alternator into dc voltage. The dc voltage is converted back to line frequency ac by the second converter, and power is fed into the grid. Similar topology is useful in four-quadrant motor drives, where the power flow is from the grid to the machine during motoring mode and from the machine to the grid during regeneration (Rashid 2001).

On account of a wide range of applications, use of VSC is widespread in power electronic industry. Also, the available ratings of insulated gate bi-polar junction transistors (IGBT) are fast increasing (Krug et al 2007). Currently IGBTs with blocking voltages of up to $6.5 \mathrm{kV}$ are available (Hiller et al 2010). With these high-voltage IGBTs, the VSC topology can be used up to a few tens of megawatt (Hiller et al 2010).

In a PWM converter, there are losses in both IGBT and its anti-parallel diode due to conduction as well as switching action. The heat generated has to be transferred safely to the surroundings 
through heat-sinks so that the semiconductor junction temperatures do not exceed their safe maximum values. To increase the rate of heat transfer, forced air cooling or liquid cooling is adopted at high power levels. The thermal system of the converter is designed to ensure that the junction temperatures are within safe limits under worst operating conditions (Bruckner \& Bernet 2007).

To prevent device failures on account of thermal run-away (over-temperature), it is necessary to verify the thermal design of the converter at the development stage or before installation. Hence, the converters are usually subjected to heat-run tests. At higher power level, this requires a high-capacity source along with a huge resistor bank as load. These may not always be available at the development center or the production facility. Further, as the converter needs to be tested at rated voltage and rated current for a good length of time (several times the thermal time constant of the converter), enormous amount of energy is expended during the test, significantly adding to the development or production cost.

Numerous attempts have been made to reduce the energy consumed during such tests. A survey on existing heat-run test methods for high-power converters is presented in section 2 . In section 3, the proposed test set-up and its advantages are presented. A control scheme for the two converters in the experimental set-up is proposed and validated in sections 4 and 5, respectively.

A few results pertaining to the control scheme have been presented in an earlier conference publication (Siva Prasad \& Narayanan 2010). Extensive results pertaining to heat-run test on high-power converter (section 8) are presented in this paper. Further, the usefulness of this test method for space-vector modulated inverters is demonstrated here (section 6). Furthermore, the influence of carrier interleaving on the quality of the input current waveform is also studied (section 7).

\section{Existing test methods}

Numerous attempts have been made to reduce the energy consumption during the testing phase of PWM converters (Siva Prasad \& Narayanan 2010; Forest et al 2006; Oates 1999; Bryant et al 2007; Huang \& Pai 2002; Lin et al 1997; Tsai 2000; Zhou et al 2008; She et al 2009; Ghosh 2007). The basic approach is to connect a tested converter (or a set of converters) with the converter under test in a back-back fashion; the two (sets of) converters are controlled such that rated power circulates through them with only the losses being drawn from the power source. As shown in figure 4, the two back-back connected converters can be fed from a dc supply, which itself may be derived from ac mains through rectification (Bruckner \& Bernet 2007; Forest et al 2006; Oates 1999; Bryant et al 2007). Alternatively, the two (sets of) converters could be fed directly from the ac mains as illustrated in figure 5 (Huang \& Pai 2002; Lin et al 1997; Tsai 2000; Zhou et al 2008; She et al 2009; Ghosh 2007).

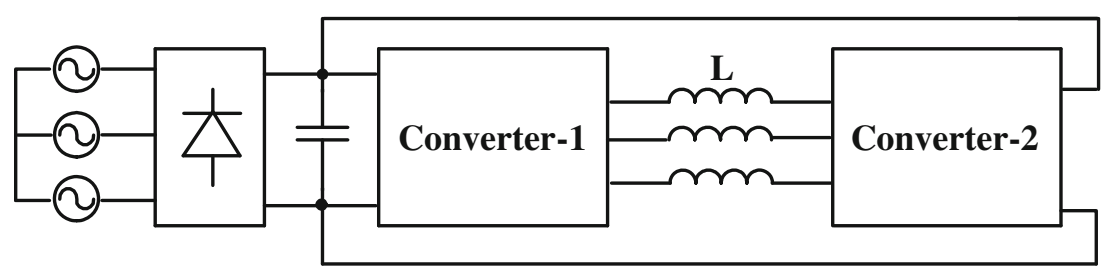

Figure 4. Back-to-back connected converters fed from a dc supply. 


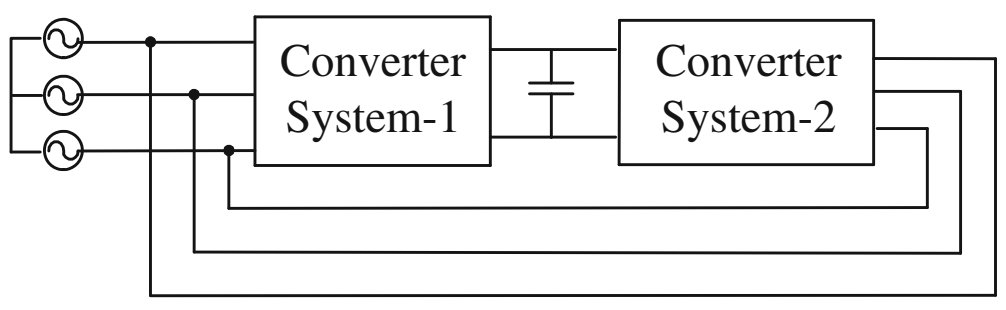

Figure 5. Back-to-back connected converters fed from ac mains.

In the testing arrangement shown in figure 4, line voltage of required magnitude and frequency is produced by modulating converter 1 in an open loop fashion. An opposing voltage is produced by converter 2, which is controlled in a closed loop fashion. Hence this method is sometimes referred to as 'opposition method' (Forest et al 2006). The amplitude and phase of the opposing voltage are chosen to ensure that the line currents have the desired amplitude and phase as illustrated in figure $3 b$.

In this method, the entire dc bus voltage gets applied across the line inductor (L) during certain switching intervals. The line-inductors being low valued, particularly at high current ratings, the current shoots up very fast and needs to be limited. Therefore specially designed control strategies are required for testing the converters (Bruckner \& Bernet 2007; Forest et al 2006; Oates 1999; Bryant et al 2007).

On the other hand, standard and well-known control methods for grid-connected converters can be adopted for the testing arrangement shown in figure 5. The term 'converter system' is used here to include line reactors and transformer, if any. One of the two converters in figure 5 is the PWM converter under test (say converter system 1). Since this is essentially a three-phase ac-dc boost converter, the dc bus voltage is higher than the peak line-line voltage of the mains (Siva Prasad et al 2008). The other converter system may consist of a diode bridge rectifier, whose $\mathrm{dc}$ bus voltage is less than the peak line-line voltage (Siva Prasad et al 2008). Hence, to meet the dc voltage requirement, the diode bridge is either fed from a step-up transformer (Huang \& Pai 2002; Lin et al 1997) or is followed by a dc-dc boost stage (Tsai 2000). Alternatively, the second converter could also be a PWM converter with rating similar to or higher than that of the converter under test (Ghosh 2007).

The converter system 2 can simply be another PWM converter of rating similar to or higher than that of converter system 1 (Ghosh 2007). While a large amount of real and/or reactive power (close to the rated $\mathrm{kVA}$ of the converters) is circulated between the converters, only a small amount of power corresponding to the losses in the system is drawn from the mains. As the converters are connected on both ac and dc sides, circulating currents flow between them (Ghosh 2007).

The issue of zero-sequence circulating currents between the converters has been studied extensively in the context of parallel-connected ac-dc PWM converters with a common dc bus, sharing a dc load (Ye et al 2002; Pan \& Liao 2007; Neacsu et al 2008; Chen 2009; Cai et al 2008; Asiminoaei et al 2008; Mao et al 2011; Zhang et al 2010, 2011). The similarity between the parallel-connected converters and back-to-back connected converters can be seen easily. In both the cases, the converters are connected on the ac as well as on the dc sides. Hence, the study on circulating currents and its mitigation in the context of parallel-connected converters is equally applicable to the back-to-back connected converters and vice versa. 
To block/reduce the circulating currents in back-to-back converters, either an isolation transformer is used on the ac side (Zhou et al 2008; She et al 2009), or a zero-sequence current controller is included in the control scheme of one of the converters (Ghosh 2007; Ye et al 2002; Pan \& Liao 2007).

Converters are increasingly operated with space vector PWM (SVPWM) due to better utilization of dc bus than sine-triangle PWM (SPWM) (Zhou \& Wang 2002). For a given dc bus voltage,

Converter -1

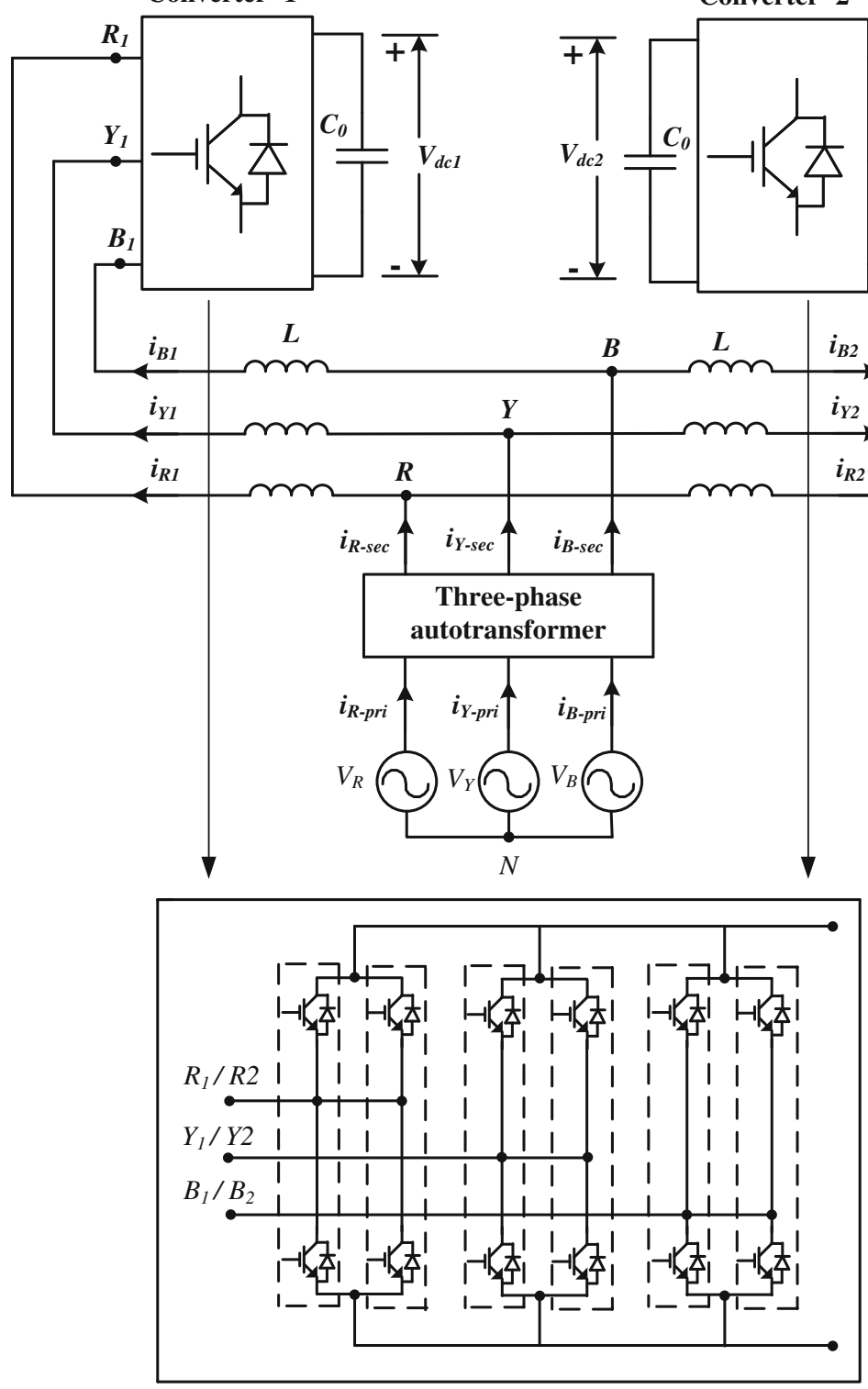

Figure 6. Schematic diagram of the proposed experimental set-up. 
SVPWM can produce a higher line-side voltage than SPWM. Conversely, for a given line-side voltage, the converter could be operated with a reduced dc bus voltage in case of SVPWM. The losses in the converter are functions of both the PWM method employed and dc bus voltage. Hence, if a converter is intended to be operated with SVPWM at a particular dc bus voltage, then its thermal testing should be carried out with the same modulation method and at the same dc bus voltage for the results to be realistic.

SVPWM involves addition of common-mode voltage to the three-phase sinusoidal modulating waves (Zhou \& Wang 2002; Varma \& Narayanan 2006). If the converters in figure 5 are modulated using this method, then excessive circulating currents would flow between them owing to the common-mode voltage injected. Hence, the configuration in figure 5 is not suitable for conducting heat-run test on converters operated with SVPWM (Ghosh 2007).

In the following section, a new test method is proposed for conducting heat-run test on highpower voltage source converters including those modulated with SVPWM.

\section{Proposed testing method}

The proposed testing arrangement is shown in figure 6. Two high-power PWM converters are connected in parallel on the ac side to the grid (similar to figure 5). But on the dc side, their dc buses are separated and open. The converters are controlled such that the line current drawn by one of them lags the supply voltage by $90^{\circ}$, while the other converter draws an equal amount of current, leading the supply voltage by $90^{\circ}$. As the two currents are in phase opposition, they cancel each other (figure 7); the net current drawn from the grid is ideally zero. In practice, the net current is very low, and accounts mainly for the losses in the system. Hence, the energy consumed to conduct this test is very nominal.

With this method, both the converters can be tested (though only at zero power factor) at their rated voltages and currents, despite the absence of high-capacity source and load arrangements. Standard control methods for such line-side converters can be adopted (explained in section 4). Also, converters operated with modulation methods involving common-mode voltage injection such as SVPWM can be tested. Due to the above-mentioned advantages, the proposed test procedure is very much useful for practicing engineers responsible for testing and certifying high-power converters. Using the above mentioned test procedure, the performance of a $150 \mathrm{kVA}$ line-side PWM converter is verified in this paper.

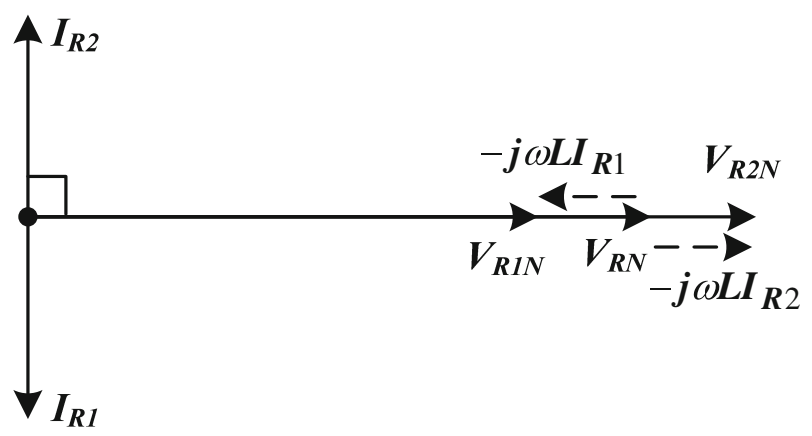

Figure 7. Phasor diagram of the test set-up. 
Vector control or field-oriented control of a line-side converter is explained in (Siva Prasad et al 2008). In the following section, this scheme is extended for controlling the two PWM converters, shown in figure 6.

\section{Control scheme}

The converters are controlled using well-known vector-control or synchronous reference frame control (Siva Prasad et al 2008; Suh \& Lipo 2006; Xiao et al 2008), which is popular for lineside converters. The block diagram of the controller used for converter 1 is shown in figure 8 (Siva Prasad et al 2008).

The outer voltage loop (figure 8) controls the dc bus voltage to be equal to the set reference. The feedback signal corresponding to the dc bus voltage is subtracted from the reference signal $\left(V_{d c 1}{ }^{*}\right)$ and the voltage error is processed through a PI controller. The output of the voltage controller corresponds to the real power reference $\left(I_{s 1 q}{ }^{*}\right)$. The $d$-axis current reference $\left(I_{s d 1}{ }^{*}\right)$ corresponds to the reactive power to be drawn or injected by the converter.

Two of the phase voltages are sensed, and are used to generate the unit-vector. The sensed converter currents and the grid voltages are converted into $d q$ reference frame using the unitvectors as shown figure 8 (Siva Prasad et al 2008).

The feedback signals corresponding to the $q$ and $d$ axis components of the converter current $\left(i_{s 1 q}\right.$ and $i_{s 1 d}$, respectively), are subtracted from their respective reference signals. The current errors are processed through their respective PI controllers. The outputs of the current controllers are added with appropriate feed-forward signals to achieve decoupling between the real and reactive powers handled by the converter. The reference signals, thus obtained in $d q$ frame, are
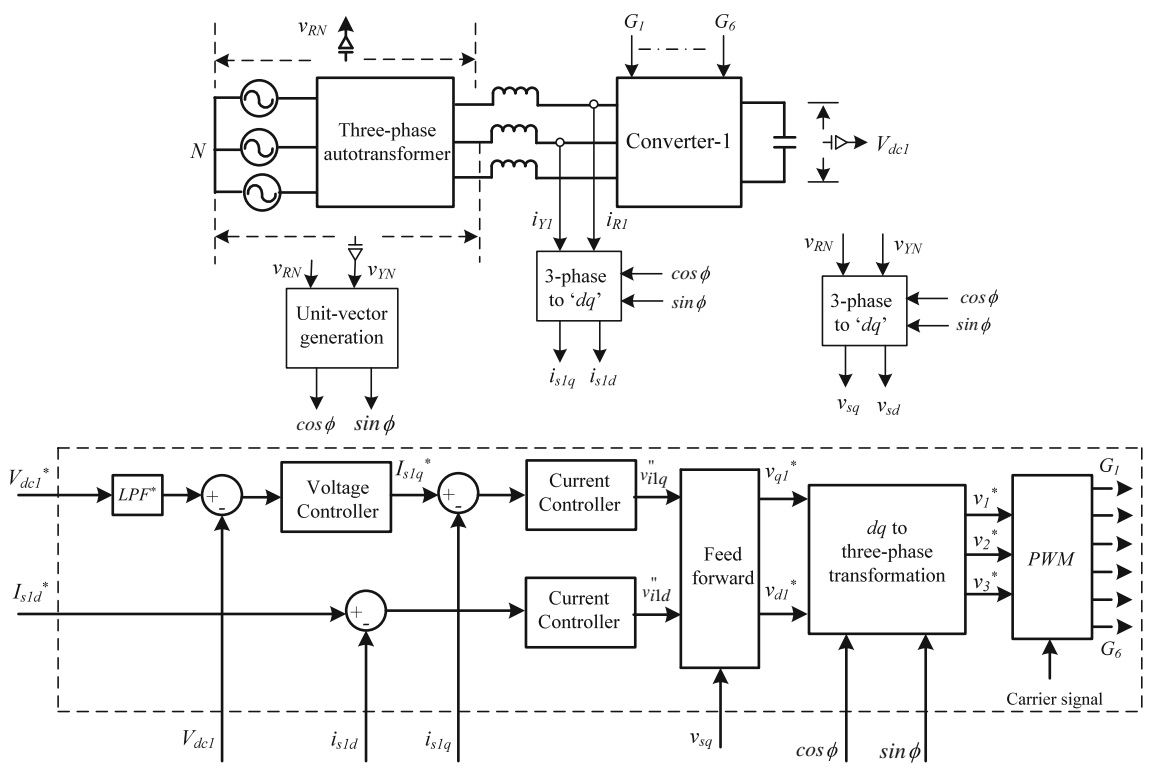

Figure 8. Block diagram of the controller for converter 1. 
converted into three-phase modulating signals. These modulating signals are compared with a common triangular carrier to generate gate pulses as shown.

A detailed discussion on modelling of the converter in the $d q$ reference frame, unit-vector generation, and selection of controller parameters for the voltage and current loops is presented in Siva Prasad et al (2008).

The control structure of converter 2 is similar to that of converter 1 . As the aim of the controller is to circulate reactive power between the converters, the reactive power reference command $I_{s d 1}{ }^{*}$ of converter 1 is negated and fed as the reference for converter 2 . This ensures that the entire reactive current circulates between the two converters with only the system losses being drawn from the grid. Further, the dc bus voltage is maintained to be equal in both the converters by providing the same reference signal $\left(V_{d c 1}{ }^{*}\right)$ for both of them.

The control scheme for the two converters in figure 6 is validated through simulation and experiments in the following section.

\section{Validation of control scheme}

The experimental set-up (figure 6) consists of two identical PWM converters, connected in parallel on the ac side. In both the converters, two 300A, $1200 \mathrm{~V}$ IGBT half-bridge modules (SKM300GB124D) (http://www.semikron.com/products/data/cur/assets/skm300GB124D 2890280.pdf) are connected in parallel (as shown in figure 6). The per-phase inductance $(L)$ of the filter inductor is $260 \mu \mathrm{H}$, and the dc bus capacitance $\left(C_{0}\right)$ is $6750 \mu \mathrm{F}$.

The converters are fed from a $100 \mathrm{kVA}, 50 \mathrm{~Hz}$ autotransformer (figure 6). While the nominal rms line voltage on the primary is $415 \mathrm{~V}$, the converters are fed from the $90 \%$ tap (on the secondary) of the autotransformer. The dc bus voltage is maintained at $700 \mathrm{~V}$. A common carrier wave of $5 \mathrm{kHz}$ frequency is used for both the converters and sine-triangle PWM is employed.
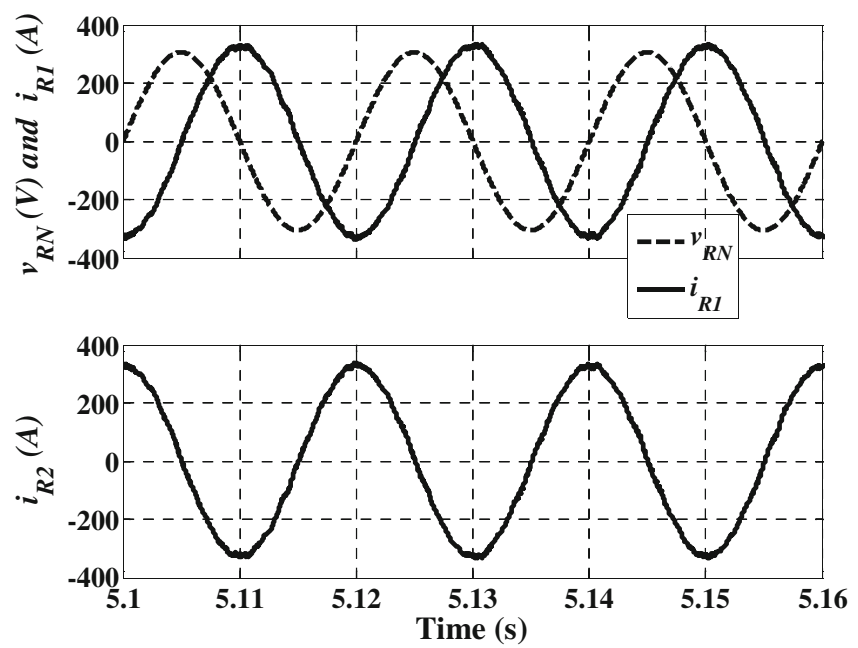

Figure 9. Supply voltage and line currents of the two converters at a reactive power reference of $150 \mathrm{kVA}$ (simulation result). 

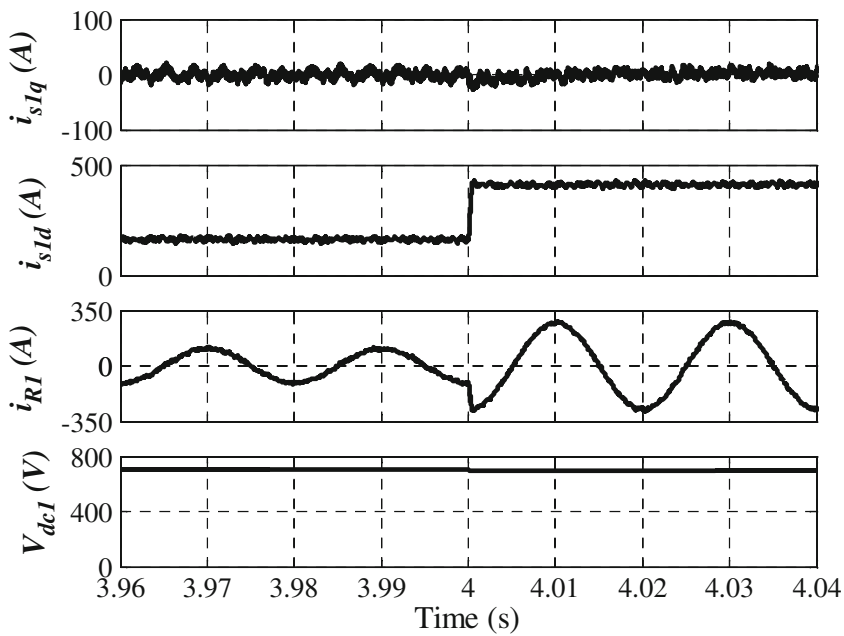

Figure 10. Transient response of the converter for a step change in reactive power reference from $50 \mathrm{kVA}$ to $125 \mathrm{kVA}$ (simulation result).

\subsection{Simulation results}

The proposed set-up is simulated using MATLAB/ Simulink. Figure 9 shows the grid voltage $\left(v_{R N}\right)$, and the converter currents $i_{R 1}$ and $i_{R 2}$ at a reactive power reference of $150 \mathrm{kVA}$. It can be observed that $i_{R 1}$ and $i_{R 2}$ are out of phase. Also, $i_{R 1}$ lags the supply voltage by $90^{\circ}$ while $i_{R 2}$ leads it by $90^{\circ}$. The net current drawn from mains $\left(i_{R-s e c}\right)$ is ideally zero as mentioned earlier.

In figure 10, the transient response of the converter is shown. The reactive power reference is changed from $50 \mathrm{kVA}$ to $125 \mathrm{kVA}$ in step. The reactive component of current $\left(i_{s 1 d}\right)$ reaches its final value very quickly, while the real power component of current $\left(i_{s 1 q}\right)$ is practically undisturbed around zero. This shows the decoupling between the real and reactive power components. The dc bus voltage remains unchanged.

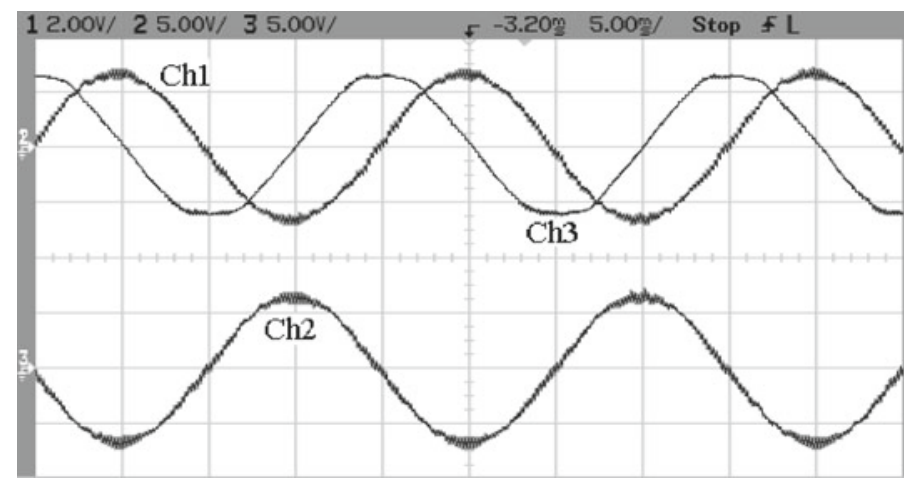

Figure 11. Supply voltage $\left(v_{R N}\right)$ and line currents $\left(i_{R 1}\right.$ and $\left.i_{R 2}\right)$ of the two converters at a reactive power reference of $150 \mathrm{kVA}$ (experimental result). Ch1- $i_{R 1}$ and Ch2- $i_{R 2}, 250 \mathrm{~A} / \mathrm{div} ., \mathrm{Ch} 3: v_{R N}, 240 \mathrm{~V} / \mathrm{div}$. 


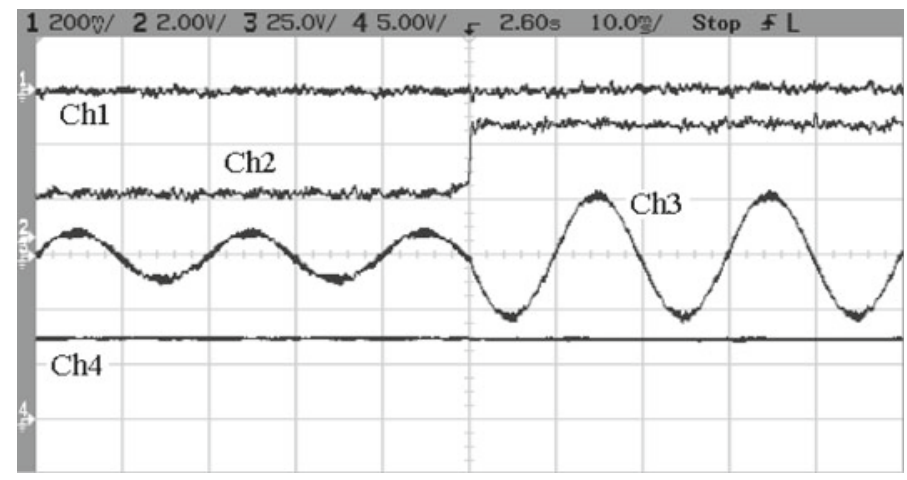

Figure 12. Transient response for a step change in reactive power reference from $50 \mathrm{kVA}$ to $125 \mathrm{kVA}$ (experimental result). Ch1- $i_{s 1 q}, \mathrm{Ch} 2-i_{s 1 d}, \mathrm{Ch} 3-i_{R 1}, \mathrm{Ch} 4-V_{d c}$. Ch1, Ch2: $210 \mathrm{~A} / \mathrm{div} ., \mathrm{Ch} 3: 250 \mathrm{~A} / \mathrm{div}$., Ch4: $450 \mathrm{~V} / \mathrm{div}$.

\subsection{Experimental results}

Both the converters in figure 6 are controlled from a single digital controller based on TMS320LF2407 DSP processor (Texas Instruments 1990). The experimental results are presented in figures 11,12 and 13.

In figure 11, the traces Ch1 and Ch2 indicate the converter currents $i_{R 1}$ and $i_{R 2}$, respectively, for a reactive power reference of $150 \mathrm{kVA}$. The trace $\mathrm{Ch} 3$ shows the supply voltage $v_{R N}$, suitably scaled for control purpose. It can be observed that $i_{R 1}$ lags $v_{R N}$ by $90^{\circ}$, while $i_{R 2}$ leads the same by $90^{\circ}$; the converter currents $i_{R 1}$ and $i_{R 2}$ are out of phase.

Figure 12 shows the transient response of the system for a step change in reactive power reference $\left(I_{s 1 d}^{*}\right)$ from $50 \mathrm{kVA}$ to $125 \mathrm{kVA}$. Ch2 shows the signal proportional to the reactive power handled by converter $1\left(i_{s 1 d}\right)$, while $\mathrm{Ch} 3$ presents the line current $i_{R 1}$. Both these signals attain their final values quickly. Ch1 and Ch4 represent the real power signal $\left(i_{s 1 q}\right)$ and the dc bus voltage $\left(V_{d c}\right)$, respectively, of converter 1 . Both these signals are unaffected by the change in the reactive power reference, confirming the decoupling between the real and reactive power flows.

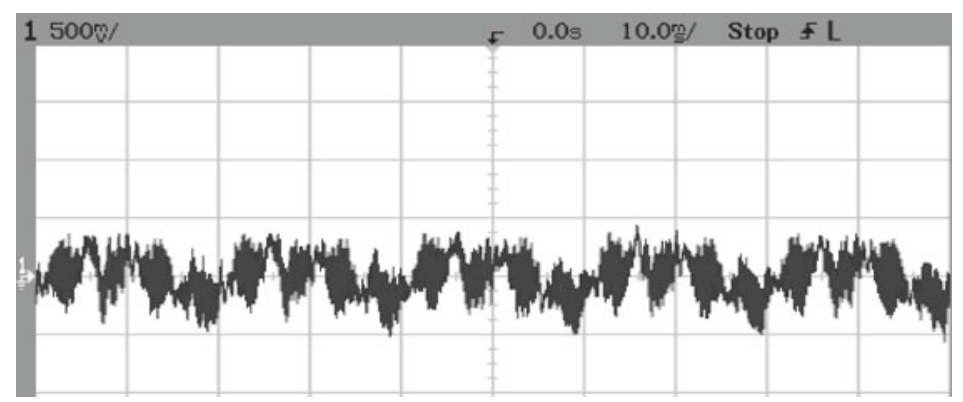

Figure 13. Measured grid current $\left(i_{R-s e c}\right)$ with a common carrier wave for the two converters at $150 \mathrm{kVA}$ reactive power circulation $(50 \mathrm{~A} /$ div.) (experimental result). 
Figure 13 shows the transformer secondary current $\left(i_{R \text {-sec }}\right)$ at $150 \mathrm{kVA}$ reactive power circulation. Though the current is highly distorted, its fundamental component is quite small, as compared to the line current of the individual converters.

\section{Modulation with SVPWM}

As mentioned earlier, SVPWM is increasingly employed for VSC topology because of its advantages in terms of dc bus utilization and line current distortion (Zhou \& Wang 2002). Hence, the proposed heat-run test method should be capable of testing PWM converters operated with SVPWM.

When reactive power is circulated between the two converters, their terminal voltages $\left(V_{R 1 N}\right.$ and $\left.V_{R 2 N}\right)$ are in-phase with the grid voltage as shown by the phasor diagram in figure 7 . Hence the modulating waves (of a particular phase) of the two converters are in-phase with each other. However, the modulating waves differ in amplitude since the corresponding terminal voltages $\left(V_{R 1 N}\right.$ and $\left.V_{R 2 N}\right)$ have different amplitudes. Hence, the common-mode voltages of the two converters with SVPWM are different (Zhou \& Wang 2002).

The difference in injected common-mode voltages of the two converters causes large circulating currents in the back-to-back test set-up shown in figure 5 (Ghosh 2007; Chen 2009). In the back-to-back connected converters, the sum of the six converter currents (i.e., $i_{R 1}+i_{Y 1}+i_{B 1}+i_{R 2}$ $\left.+i_{Y 2}+i_{B 2}\right)$ is equal to zero. But the sum of the three line-currents of an individual converter (either $i_{R 1}+i_{Y 1}+i_{B 1}$ or $i_{R 2}+i_{Y 2}+i_{B 2}$ ) is not equal to zero. Hence, zero-sequence currents exist in this experimental set-up.

However, in the proposed experimental set-up (figure 6), the converters are separated on the $\mathrm{dc}$ side; the sum of the three line currents of both converters $\left(i_{R 1}+i_{Y 1}+i_{B 1}\right)$ and $\left(i_{R 2}+i_{Y 2}+\right.$ $\left.i_{B 2}\right)$ are equal to zero. Hence, the zero-sequence circulating currents are absent in this test setup. Hence, SVPWM can be employed, even with injection of different common-mode voltages on the two converters, as demonstrated by the following experimental results.

Figure 14 shows the R-phase modulating wave (Ch1), R-phase current (Ch2), Y-phase current (Ch3) and the sum of the three phase currents $\left(i_{R 1}+i_{Y 1}+i_{B 1}\right)(\mathrm{Ch} 4)$, all pertaining to converter 1 , for $150 \mathrm{kVA}$ reactive power circulation. Sine-triangle PWM is employed. As should be

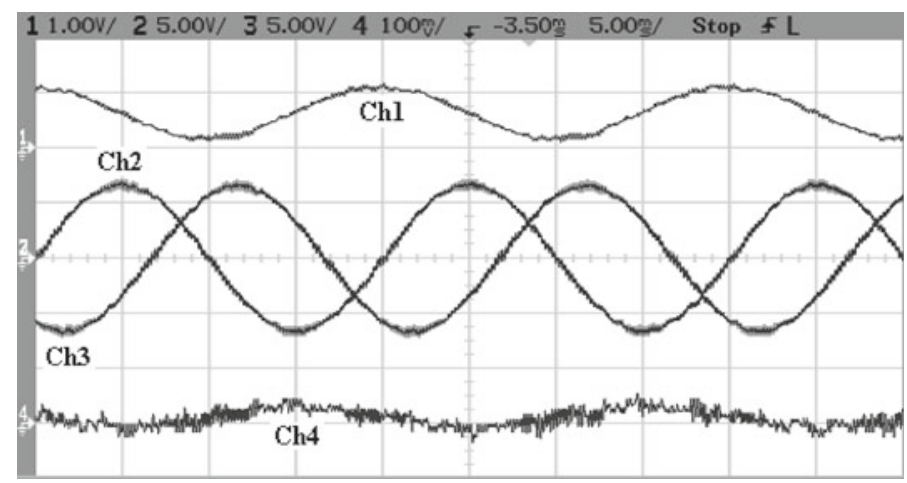

Figure 14. Measured current waveforms with Sine-triangle PWM, at $150 \mathrm{kVA}$ reactive power circulation Ch1 - modulating wave $\left(v_{1}{ }^{*}\right), \mathrm{Ch} 2-i_{R 1}, 250 \mathrm{~A} /$ div., Ch3 - $i_{Y 1}, 250 \mathrm{~A} /$ div., Ch4 $-\left(i_{R 1}+i_{Y 1}+i_{B 1}\right), 10 \mathrm{~A} /$ div. 


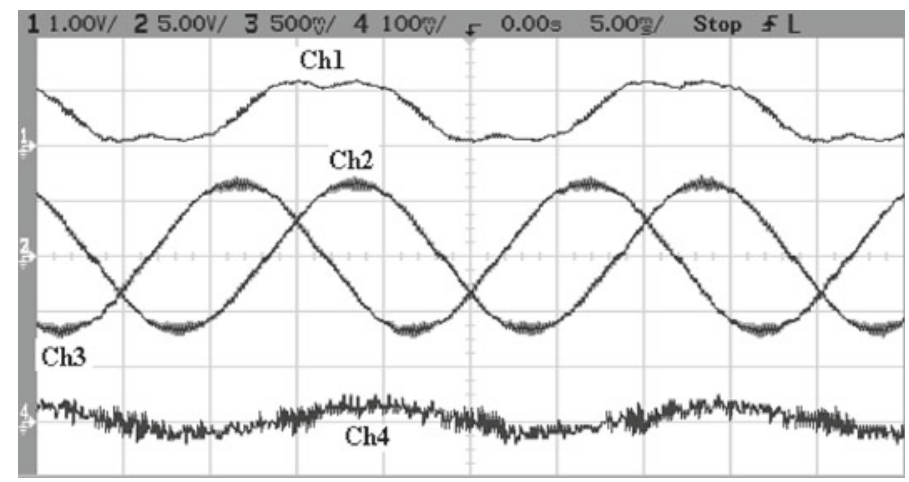

Figure 15. Measured current waveforms with SVPWM, at $150 \mathrm{kVA}$ reactive power circulation. Ch1modulating wave $\left(v_{1}^{*}\right), \mathrm{Ch} 2-i_{R 1}, 250 \mathrm{~A} /$ div., Ch3- $i_{Y 1}, 250 \mathrm{~A} /$ div., Ch4 $-\left(i_{R 1}+i_{Y 1}+i_{B 1}\right), 10 \mathrm{~A} / \mathrm{div}$.

expected, no significant zero-sequence circulating currents are observed (Varma \& Narayanan 2006).

Similar results are shown in figure 15, with SVPWM. In this case also the zero-sequence currents are insignificant.

Thus, the circulating currents are insignificant even if different common-mode voltages are injected in the two converters. Hence, the proposed test set-up can be used for heat-run test on space vector modulated converters without any problem of circulating currents.

\section{Carrier interleaving}

In this section, the effect of carrier interleaving or phase-shifting of the carriers of the two converters on the quality of the input current waveform drawn by the test set-up is studied.

In the proposed experimental set-up, the grid current is equal to the sum of the two individual converter currents, as can be observed from figure 6 . The converter currents can be divided into the fundamental and high-frequency ripple components. If losses are ignored, the fundamental components of the two converter currents are out of phase; hence they cancel each other. But,

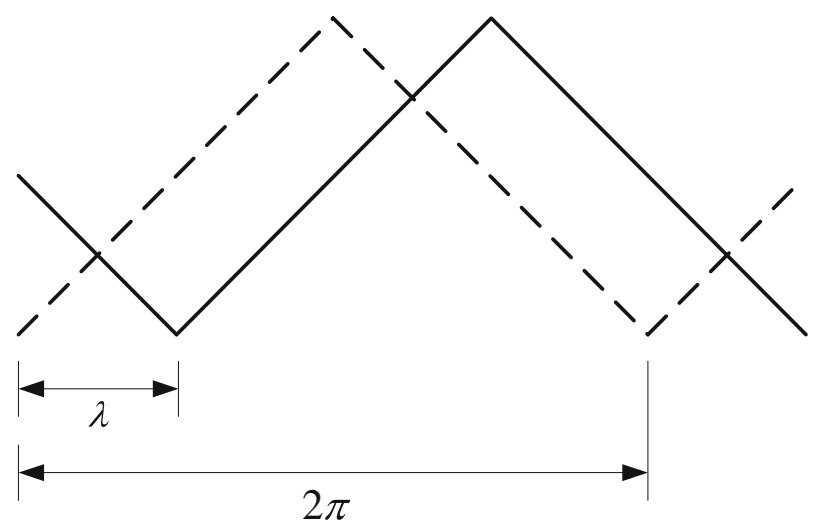

Figure 16. Interleaving of carrier signals. 


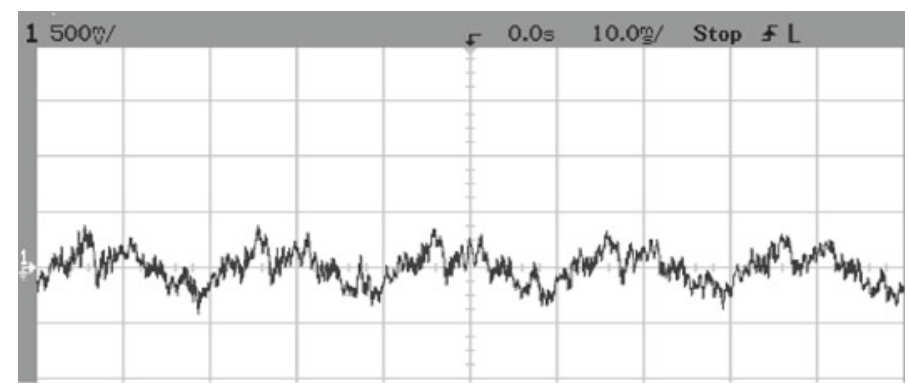

Figure 17. Measured grid current $\left(i_{R-s e c}\right)$ with interleaved carriers at $150 \mathrm{kVA}$ reactive power circulation (50 A/div.).

the sum of the ripple components flow from the mains; this is seen as high frequency distortion in the grid current waveform in figure 13.

The waveform in figure 13 is obtained when the same carrier is used for both the converters. But the carrier signals of the two converters can be phase shifted by certain angle $\lambda$ (at the carrier frequency) as illustrated in figure 16 (Asiminoaei et al 2008; Mao et al 2011; Zhang et al 2010, 2011). When $\lambda=180^{\circ}$, i.e., when the two carriers are out of phase (Asiminoaei et al 2008; Mao et al 2011; Zhang et al 2010, 2011), the grid current waveform drawn by the experimental set-up is as shown in figure 17. As seen from figures 13 and 17, the high frequency component of the input current waveform reduces on account of phase shifting the carrier signals by $180^{\circ}$. This can be attributed to cancellation, to certain extent, of the switching-frequency harmonic currents drawn by the two converters. However, interleaving does not have any appreciable effect on the waveform quality of the individual converter currents as can be observed from figures 15 and 18 .

Even with interleaving, the grid current waveform is considerably distorted with lower order harmonic components. This can be attributed to the source voltage being polluted with lower order harmonics (see figure 11). The source current can be improved by employing suitable control methods that take mains voltage distortion into account (Suh \& Lipo 2006; Xiao et al 2008).

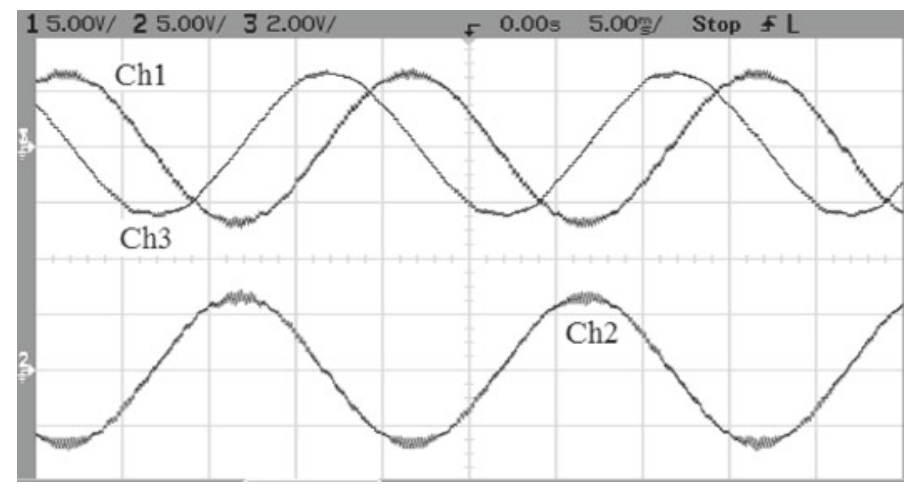

Figure 18. Measured supply voltage $\left(v_{R N}\right)$ and line currents of the two converters at $150 \mathrm{kVA}$ reactive power circulation. Ch1- $i_{R 1}$ and Ch2- $i_{R 2}, 250 \mathrm{~A} /$ div., Ch3: $v_{R N}, 240 \mathrm{~V} /$ div. (Interleaved with $\lambda=180^{\circ}$ ). 


\section{Heat-run test}

Using the above mentioned control and modulation methods, heat-run test is carried out on the converters considered. The two parallel-connected IGBT modules in each phase are mounted on separate heat sinks, shown by the dashed lines in figure 6 . Hence, there are six heat-sinks present in each converter. Figure 19 shows the measured heat-sink temperature of one of the two converters at $150 \mathrm{kVA}$ reactive power circulation. $\Delta \mathrm{T}$ indicates the rise in temperature above ambient. T-type thermo couples are used for temperature measurement (http://www.fluke.com/ fluke/usen/Electrical-Test-Tools/Thermometer/Fluke-50-series-II.htm). In the figure, (R1, R2) indicate the temperatures of the two-parallel connected modules of R-phase. Similarly Y1, Y2 and B1, B2 indicate the heat-sink temperatures of the other two phases. It can be observed that the temperatures reach to a steady value. The difference in steady state temperatures of B1 and $\mathrm{B} 2$, for instance, is indicative of the difference in current sharing between the parallel-connected modules.

Table 1 shows the average of the six-heat sink temperatures at different kVA levels along with the power input to the set-up, measured at the secondary side of the autotransformer (figure 6). As kVA level increases, losses in the system and hence the heat-sink temperature increases.

Evidently, no resistive loading arrangement is required as the converters are open on the dc side. Also, the converters are loaded up to $150 \mathrm{kVA}$, which is more than the rating of the autotransformer (100 kVA) in figure 6. Hence, with the proposed test method, the converters can be tested at a kVA level higher than the rating of the upstream power equipment.

Further, the total power input to the system is quite low, as compared with the loading on the individual converters. For example, the total power consumed for heat-run test on converters at a power level of $150 \mathrm{kVA}$ is less than $7.5 \mathrm{~kW}$ as seen from table 1 . Thus the energy consumed for a 90 min heat-run test (figure 19) is only around $11.3 \mathrm{kWh}$. On the other hand, if a single converter were tested at $150 \mathrm{~kW}$ with resistive loading, the energy consumed would have been around $225 \mathrm{kWh}$ for a $90 \mathrm{~min}$ heat-run test. Thus, the proposed test procedure results in significant energy saving.

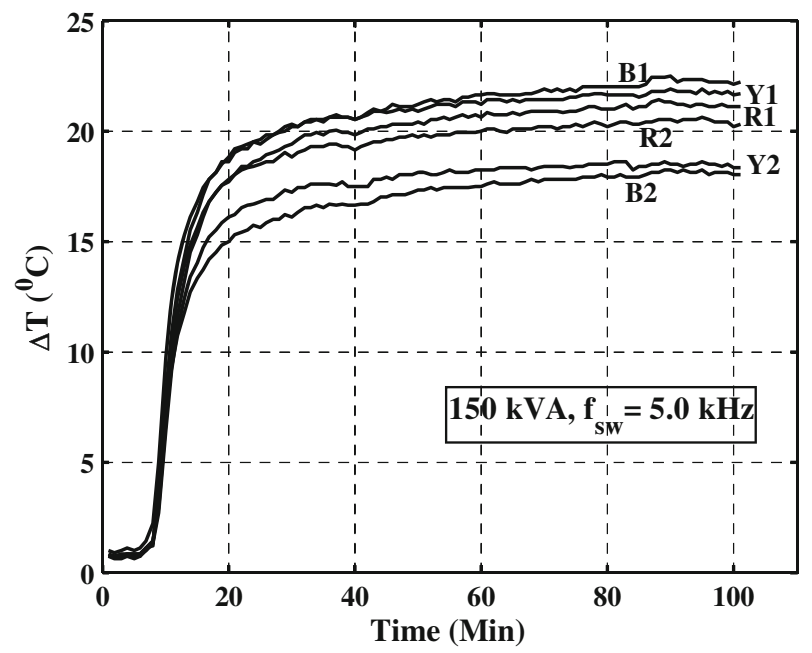

Figure 19. Measured heat-sink temperatures at $150 \mathrm{kVA}$ reactive power circulation. 
Table 1. Power input and heat-sink temperature at different kVA.

\begin{tabular}{lcccccc}
\hline $\mathrm{kVA}$ & 25 & 50 & 75 & 100 & 125 & 150 \\
$\Delta \mathrm{T}\left({ }^{\circ} \mathrm{C}\right)$ & 4.2 & 6.9 & 9.2 & 13.2 & 16.8 & 20.2 \\
$\mathrm{P}_{\text {input }}(\mathrm{W})$ & 1730 & 2485 & 3450 & 4618 & 5844 & 7343 \\
\hline
\end{tabular}

\section{Conclusion}

An apparatus and method to conduct heat-run test on line-side PWM converters with minimum energy-consumption from the mains are presented. With the proposed test procedure, the converters can be tested at a kVA level higher than the power source capacity. The test does not require any high capacity loads (e. g., resistor banks) either.

The test method does not have the problem of circulating currents, commonly associated with circulating power or regenerative test methods for power converters. Hence as demonstrated experimentally, the test method is also useful for conducting heat-run tests on converters operated with PWM methods involving common-mode injection such as space vector modulation.

The proposed test method is much useful for practicing engineers charged with testing and qualifying high-power converters.

\section{References}

Asiminoaei L, Aeloiza E, Enjeti P N and Blaabjerg F 2008 Shunt active-power-filter topology based on parallel interleaved inverters. IEEE Trans. Ind. Electron. 55(3): 1175-1189

Bruckner T and Bernet S 2007 Estimation and measurement of junction temperatures in a three-level voltage source converter. IEEE Trans. Power Electron. 22(1): 3-12

Bryant A T, Allotey N A P and Palmer P R 2007 The use of condition maps in the design and testing of power electronic circuits and devices. IEEE Trans. Ind. Appl. 43(4): 902-910

Cai H, Zhao R and Yang H 2008 Study on ideal operation status of parallel inverters. IEEE Trans. Power Electron. 23(6): 2964-2969

Chen T P 2009 Dual-modulator compensation technique for parallel inverters using space-vector modulation. IEEE Trans. Ind. Electron. 56(8): 3004-3012

Forest F, Huselstein J J, Faucher S, Elghazouani M, Ladoux P, Meynard T A, Richardeau F and Turpin C 2006 Use of opposition method in the test of high-power electronic converters. IEEE Trans. Ind. Electron. 53(2): 530-541

Ghosh R 2007 Modeling, Analysis and Control of Single-phase and Three-phase PWM Rectifiers. Ph.D Thesis, Indian Institute of Science, Bangalore, May 2007

Hiller M, Sommer R, Beuermann M 2010 Medium voltage drives. IEEE Industry Appl. Magazine, Mar./Apr. 22-30

http://www.fluke.com/fluke/usen/Electrical-Test-Tools/Thermometer/Fluke-50-series-II.htm (accessed on 12-05-11)

http://www.semikron.com/products/data/cur/assets/skm300GB124D_2890280.pdf (accessed on 12-05-11)

Huang S J and Pai F S 2002 Design and operation of burn-in test system for three-phase uninterruptible power supplies. IEEE Trans. Ind. Electron. 49(1): 256-263

Kadri R, Gaubert J P and Champenois G 2011 An improved maximum power point tracking for photovoltaic grid-connected inverter based on voltage-oriented control. IEEE Trans. Ind. Electron. 58(1): $66-75$

Krug D, Bernet S, Fazel S. A, Jalili K and Malinowski M 2007 Comparison of $2.3 \mathrm{kV}$ medium-voltage multilevel converters for industrial medium-voltage drives. IEEE Trans. Ind. Electron. 54(6): 2979-2992 
Lin C E, Tsai M T, Sai W I and Huang C L 1997 Consumption power feedback unit for power electronics burn-in test. IEEE Trans. Ind. Electron. 44(2): 157-166

Mao X, Jain A K and Ayyanar R 2011 Hybrid interleaved space vector PWM for ripple reduction in modular converters. IEEE Trans. Power Electron. 26(7): 1954-1967

Neacsu D O, Wagner E and Borowy B S 2008 A simulation benchmark for selection of the PWM algorithms for three-phase interleaved converters. IEEE Trans. Ind. Electron. 55(4): 1628-1636

Oates C 1999 Accelerated life testing of a traction inverter. IEE Power Eng. J. 13(5): 263-271

Pan C T and Liao Y H 2007 Modeling and coordinate control of circulating currents in parallel three-phase boost rectifiers. IEEE Trans. Ind. Electron. 54(2): 825-838

Portillo R C, Prats M M, Leon J I, Sanchez J A, Carrasco J M, Galvan E and Franquelo L G 2006 Modeling strategy for back-to-back three-level converters applied to high-power wind turbines. IEEE Trans. Ind. Electron. 53(5): 1483-1491

Rashid M H 2001 Hand Book of Power Electronics, San Diego, California, USA: Academic Press

Sensarma P S, Padiyar K R and Ramanarayanan V 2001 Analysis and performance evaluation of a distribution STATCOM for compensating voltage fluctuations. IEEE Trans. Pow. Del. 16(2): 259-264

She X, She Y, Wang C, Tang J, Li F and Zou Y 2009 Unified power electronic load for burn-in test. Proc., Power Electronics and Motion Control Conference, IPEMC, 1803-1807

Siva Prasad J S and Narayanan G 2010 Control of parallel-connected converters for load testing of highpower PWM converters. National Power Electronics Conference, IIT Roorkee (Proceeding available in CD-ROM)

Siva Prasad J S, Bhavsar T, Ghosh R and Narayanan G 2008 Vector control of three-phase AC/DC front-end converter. Acad. Proc. Eng. Sci. Sadhana 33(5): 591-613

Suh Y and Lipo T A 2006 Control scheme in hybrid synchronous stationary frame for PWM AC/DC converter under generalized unbalanced operating conditions. IEEE Trans. Ind. Appl. 42(3): 825-835

Tsai M T 2000 Comparative investigation of the energy recycler for power electronics burn-in test. Proc. Inst. Electr. Eng.—Electr. Power Appl. 147(3): 192-198

TMS320LF/LC240X DSP Controllers Reference Guide (SPRU357). Texas Instruments, 1990

Varma P S and Narayanan G 2006 Space vector PWM as a modified form of sine-triangle PWM for simple analog/digital implementation. IETE J. Res. 52(6): 435-449

Xiao P, Corzine K A and Vengayamoorthy G K 2008 Multiple reference frame-based control of three-phase PWM boost rectifiers under unbalanced and distorted input conditions. IEEE Trans. Power Electron. 23(4): 2006-2017

Ye Z, Boroyevich D, Choi J Y and Lee F C 2002 Control of circulating current in two parallel three-phase boost rectifiers. IEEE Trans. Power Electron. 17(5): 609-615

Zhang D, Wang F, Burgo R, Lai R and Boroyevich D 2010 Impact of interleaving on AC passive components of parallel three-phase voltage-source converters. IEEE Trans. Ind. Appl. 46(3): 1042-1054

Zhang D, Wang F, Burgo R, Lai R and Boroyevich D 2011 DC-link ripple current reduction for parallel three-phase voltage-source converters with interleaving. IEEE Trans. Power Electron. 26(6): 1741-1753

Zhou Y, Wang L and Chen X 2008 Research on digital controlled converter for ac power electronics burn-in test with energy feedback. Proc., International Conference on Electrical Machines and systems, ICEMS

Zhou K and Wang D 2002 Relationship between space-vector modulation and three-phase carrier-based PWM: a comprehensive analysis. IEEE Trans. Ind. Electron. 49(1): 186-196 